\title{
A modified feeding bottle for a cleft palate infant
}

\begin{abstract}
Cleft lip and cleft palate are one of the most commonest craniofacial anomalies. In the year 2014, the rate of incidence of cleft lip and palate is 1.5 per 1000 live births worldwide. Infants suffer a lot of difficulty in sucking during the initial few days after birth. There is even psychological stress to the parents due to improper feeding and are prone to nutritional insufficiency. As advance in the medical field, there is a total repair of cleft lip and cleft palate and is performed in the later stages of infants. It is the multidisciplinary approach which includes pedodontist, oral surgeon, prosthodontist and speech therapist. In this article, the technique is highlighted to fulfill the feeding problem of infants in the early stages of birth.
\end{abstract}

Keywords: cleft palate, feeding bottle, infant

\begin{abstract}
Correspondence: Vinuta Hiremath, Department of Prosthodontics, KLEVK Institute of Dental Sciences, Belgaum 5900। 0, India, Email vinutaswamy@gmail.com
\end{abstract}

Received: September 27, 2015 | Published: November 28,

2016

\section{Introduction}

Cleft lip and palate, are the most common congenital deformities of the orofacial region. Cleft palate is the split or opening in the floor of the mouth. ${ }^{1,2}$ During the growth of the fetus, different parts of the face develop separately and then fuse together. If any disturbance in the normal fusion, then there is cleft formation. Cleft lip with or without palate affects one in 700 babies. When compared with boys, twice as many girls are affected by palate without a cleft lip. The cleft palate main problem is feeding, which is utmost essential in the early stages of infants to provide better nutrition for infants which is necessary for the growth and development. ${ }^{3,4}$ But due to the separation of palatal area, there is the improper position of breast nipple for compression and no adequate negative intraoral pressure for suction on a bottle nipple. ${ }^{5,6}$ Cleft palate infants are treated with surgery and the orthodontist, but which is corrected in the later stages of the infant's birth. ${ }^{7-9}$ So in this article, we have come with a modified feeding, which is very essential in the early stages of the infants to provide adequate nutrition through feeding.

\section{Technique}

1. A commercially available feeding bottle of $125 \mathrm{ml}$. Is taken (Figure1).

2. A plastic flexible tablespoon of appropriate size is taken and extension of spoon in the palatal area is checked.

3. A trough is made in the screw threaded cap of feeding bottle, neck part of the spoon handle is fitted completely (Figures $2 \& 3$ ).

4. The fit of the spoon handle is checked and bowl part of the spoon should cover the cleft palate area without creating any gap between the palate and bowl back of spoon.

5. Once the fit is confirmed the neck part of the spoon handle is secured into the trough with the use of self cure acrylic resin material.
6. The screw thread cap and nipple, spoon is assembled back into the body of the bottle and sterilized (Figure 4).

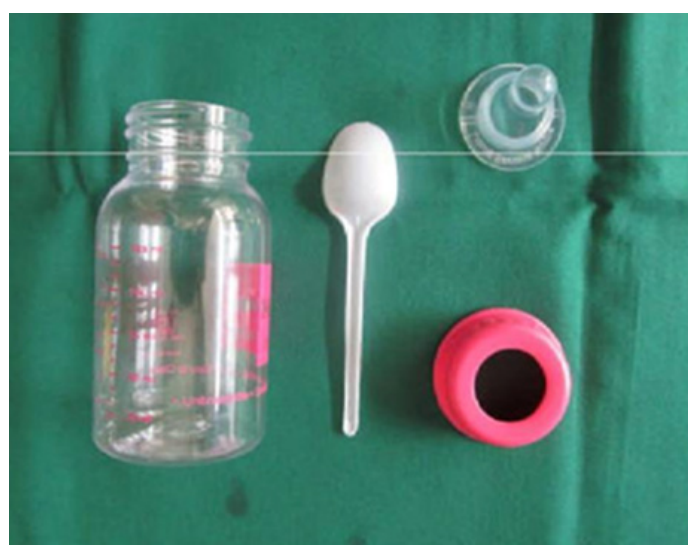

Figure I Feeding bottle with screw threaded cap, spoon and nipple.

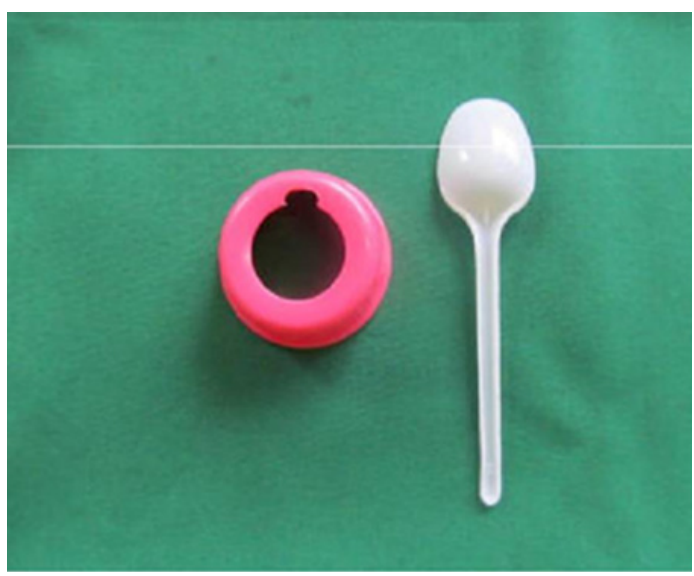

Figure $2 \mathrm{~A}$ trough made in the screw threaded cap. 


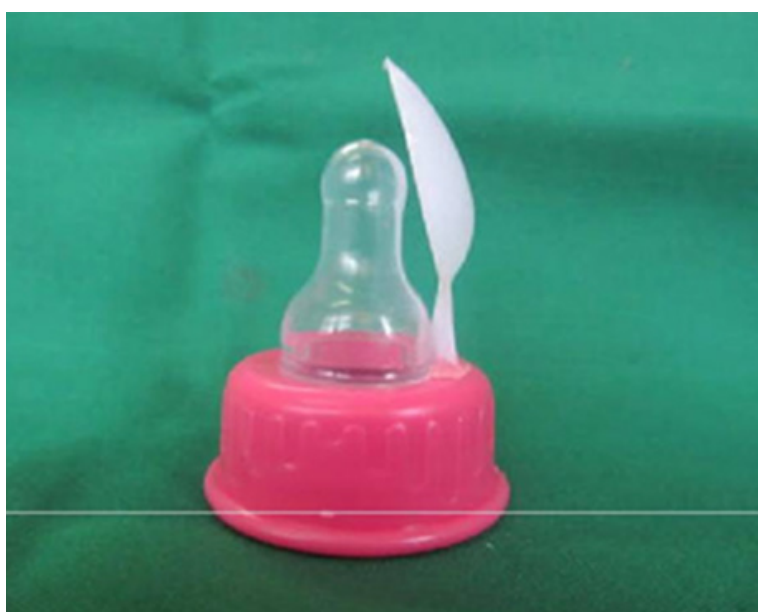

Figure 3 Neck part of the spoon handle is fitted completely.

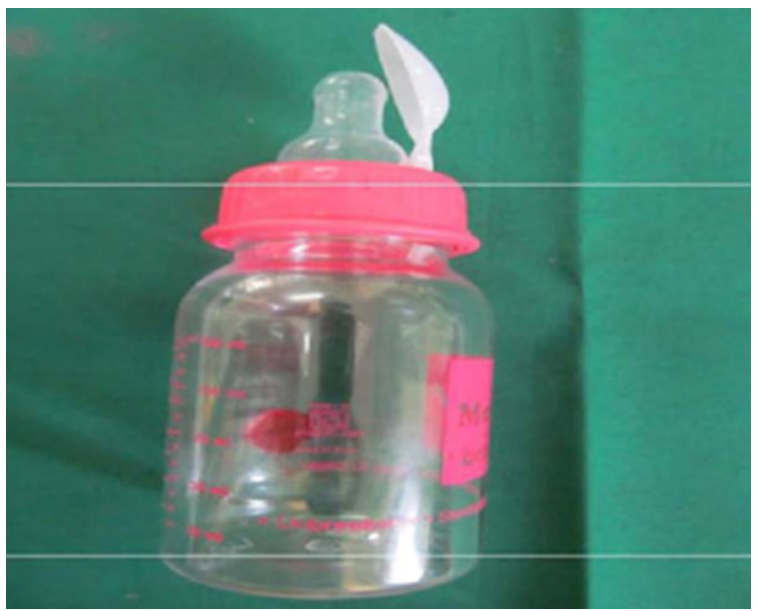

Figure 4 Neck part of the spoon handle is fitted completely.

\section{Discussion}

The main goal of cleft palate infants is maintaining a proper nutrition and a proper feeding technique for growth and development of infant and prepare the baby for corrective surgery. There are two basic tasks useful for infant feeding, sucking actions which draws the milk into the mouth and swallowing which transfer the milk from the or pharynx to stomach. ${ }^{1-4}$ It is observed that babies use different techniques to suck the milk from a bottle and from the breasts. During regular breast feeding, infant uses tongue to suck the milk from a nipple by a negative pressure and in bottle feeding infant use gums and very frequently use tongue and palate to position the nipple and create sufficient negative pressure to suck the milk. ${ }^{3-5}$ Cleft palate infant experience a difficulty in regular breastfeeding, because of improper seal of palates and sufficient sucking suction to pull milk from a nipple and infant experience problems such as excessive air intake, nasal regurgitation, inadequate milk intake; lose weight, longer duration to feed. Due to improper feeding and proper guidance, support can lead to maternal stress, anxiety and poor mother and infant bonding. ${ }^{5-9}$ A variety of artificial nipples with regular large base and long shaft, soft nipple with an enlarged outlet, large nipple base, compressible bottles and cup feeding are available. ${ }^{10,11}$ In the article modified feeding bottle was constructed it restores the oral and nasal separation during feeding and provide sufficient negative pressure; it prevented the entry of the tongue into the cleft, provides or helps to maintain the nutrition, easy to construct and smooth surface without any irritation to palatal area. This modified feeding bottle has many advantages and is useful in the initial period of infant.

\section{Why this paper is important to pediatric dentists}

The most of the problems due to cleft palate in neonate is solved by modified feeding bottle such as

a. Helps to provide proper nutrition required in initial stage of infant development.

b. Helps in promoting neonatal weight gain which is required before corrective surgery.

c. Reduces the parental stress and anxiety.

\section{Acknowledgments}

None.

\section{Conflicts of interest}

The authors declare that there are no conflicts of interest.

\section{Funding}

None.

\section{References}

1. Sree Devi E, Shankar AJ, Manoj MG, et al. Maiden Morsel-Feeding in cleft lip and palate infants. J Int Soc Prev Community Dent. 2012;2(2):31-37.

2. Ravichandra KS, Vijayaprasad KE, Vasa AA K, et al. A technique of impression making for an obturator in cleft lip and palate patient. J Indian Soc Pedod Prev Dent. 2010;28(4):311-314.

3. Osuji OO. Preparation of feeding obturators for infants with cleft lip and palate. J Clin Pediatr Dent. 1995;19(3):211-214.

4. Sterling K, Barbara Anderson, lynn S. Feeding infants with cleft lip, clef palate or cleft lip and palate. Cleft palate journal. 1987;24(3):244-249.

5. Saunders ID, Geary L, Fleming P, et al. A simplified feeding appliance for the infant with cleft lip and palate. Quintessence Int. 1989;20(12):907-910.

6. Julie reid. A review of feeding interventions for infants with cleft palate. The Cleft palate Craniofacial Journal. 2004;41(3):268-278.

7. Gunay Y, Gurbuz B, Karayazgan B, et al. A preoperative appliance for a newborn with cleft palate. Cleft palate craniofacial Journal. 2009;46(1):53-57.

8. Narendra R, Sashi P, Sashi R, et al. Feeding obturator $-\mathrm{A}$ Presurgical prosthetic aid for infants with cleft lip and palate-Clinical report. Annals and essence of dentistry. 2013;5(2):1-5.

9. Rathee M, Hooda A, Tamarkar AK, et al. Role of Feeding Plate in Cleft Palate:Case Report and Review of Literature. The Internet Journal of Otorhinolaryngology. 2010;12(1).

10. Turner Porus S, Fernandez Vivienne C. Rehabilitation of cleft lip and palate patients. Journal Indian dent asso. 1985;57(3):93-96.

11. Chandna P, Vkadlakha, Singh N. Feeding obturator appliance for an infant with cleft lip and palate. Journal of Indian Society of Pedodontics and preventive dentistry. 2011;29(1):71-73.

12. Jones JE, Henderson L, Avery DR. Use of a feeding obturator for infants with severe cleft lip and palate. Spec Care Dentist. 1982;2(3):116-120.

13. Oliver O Osuji. Preparation of feeding obturators for infants with cleft lip and palate. J of clin Pediatr Dent. 1995;19(3):211-214. 